\title{
Keragaman Jenis Jamur Endofit pada Pandan Wangi (Pandanus amarylifolius) dan Aktivitas Antijamur Metabolit yang Diproduksinya
}

\section{Biodiversity of Endophytic Fungi on Pandan Wangi (Pandanus amarylifolius) and Antifungal Activities of their Metabolites}

\author{
Yuliasri Jamal' ${ }^{1}$ Muhamad Ilyas ${ }^{2}$, Atit Kanti ${ }^{2}$, Andria Agusta ${ }^{1 *}$ \\ ${ }^{1}$ Lab. Bioproses, Bidang Botani, Puslit Biologi LIPI, Jl. Raya Bogor Km. 46, Cibinong 16911 \\ ${ }^{2}$ Lab. Biosistematika dan Kultur Koleksi Mikroba, Bidang Mikrobiologi, Puslit Biologi LIPI, Jl. Raya Bogor \\ Km. 46, Cibinong 16911 \\ E-mail: bislunatin@yahoo.com,*Penulis untuk korespondensi
}

\begin{abstract}
The whole nine isolates of endophytic fungi have been obtained from leaves and roots of pandan wangi (Pandanus amarylifolius) collected from Bogor Botanical Garden. Identification of the fungi isolates were conducted based on their morphological characteristics, and revealed that one fungus belongs to the genus of Fusarium, one of Dreschlera, and 7 fungi isolates belong to Coelomycetes. The ethyl acetate extract of the fungi cultures in PDB and GYP media showed a diverse secondary metabolite profiles. Ethyl acetate extract derived from the culture of PWA-2 fungus in GYP medium showed an antifungal activity against Saccharomyces cerevisiae, but not to Fusarium oxysporum and Candida tropicalis. The GC-MS analysis of the active extract showed eugenol as an active component.
\end{abstract}

Key words: Pandan wangi, $P$. amarylifolius, endophytic fungi, antifungal, eugenol

Diterima: 06 Oktober 2008, disetujui: 30 April 2009

\section{Pendahuluan}

Jamur memiliki biodiversitas kedua paling besar setelah serangga. Diperkirakan sebanyak 1.5 juta spesies jamur hidup tersebar di berbagai pelosok bumi, dan pada tahun 1990 dilaporkan baru sekitar 5\% (69 ribu jenis) di antaranya yang telah diketahui (Hawksworth, 1991). Setiap tahun diperkirakan sebanyak 1.700 jenis jamur baru dideskripsikan diberbagai belahan dunia (Hawksworth dan Rossman, 1997), sehingga dalam kurun waktu hampir 15 tahun (dari 1992 - 2006), diperkirakan jumlah jamur yang dikenal telah bertambah sekitar 31.000 ribu jenis jamur baru. Sampai tahun 2006 baru sekitar 6.6\% dari total jenis jamur yang ada di bumi yang telah dideskripsikan, dan masih terdapat sekitar 93.4\% (1.4 juta) jenis jamur yang masih menunggu untuk ditemukan dan diungkapkan potensinya.

Salah satu kelompok jamur yang terdapat di alam adalah jamur endofit. Jamur endofit adalah jamur yang hidup berasosiasi (simbiosis dan mutualisme) di dalam jaringan tumbuhan sehat tanpa menimbulkan tanda-tanda adanya infeksi (Bacon dan White, 2000). Dalam asosiasi mutualisme, jamur endofit akan memperoleh makanan dari tumbuhan inang, dan sebaliknya akan memberikan sesuatu, biasanya metabolit sekunder yang bermanfaat untuk fisiologi dan ekologi tumbuhan inang. (Tan dan Zou, 2001; Zhang et al., 2006).

Jamur endofit dilaporkan memiliki metabolit sekunder dengan diversitas yang tinggi. Berbagai golongan senyawa metabolit sekunder seperti alkaloid, terpenoid, kuinon, turunan isokumarin, fenilpropanoid, fenolik, dan senyawa alifatik telah diisolasi dari kultur 
in-vitro jamur endofit dalam kurun waktu 20 tahun terakhir (Tan dan Zou, 2001; Zhang et al., 2006).

Strobel dan daisy (2003) memperkirakan paling tidak ada 4 jenis jamur yang hidup berasosiasi dengan tumbuhan sebagai jamur endofit yang bersifat culturable (bisa ditumbuhkan pada kondisi artifisial). Dengan total 250.000 jenis tumbuhan yang terdapat di bumi, paling tidak akan terdapat sekitar 1 juta jenis jamur endofit di bumi dengan karakter yang berbeda satu sama lainnya. Indonesia dengan 40.000 jenis tumbuhan, paling tidak juga memiliki sekitar 160.000 jenis jamur endofit yang tersebar dari Sabang sampai ke Merauke. Eksplorasi potensi jamur endofit sebagai produsen metabolit yang aktif biologi, karakterisasi jenis jamur endofit akan menempati salah satu posisi penting dalam mata rantai penelitian jamur endofit.

Sejauh ini belum ada pengamatan tentang biodiversitas dan bioprospeksi dari jamur endofit yang hidup berasosiasi dengan tumbuhan pandan wangi (Pandanus amarylifolius). Untuk itu penelitian ini ditujukan untuk mengetahui biodiversitas dan untuk mengungkapkan potensi jamur endofit dari pandan wangi sebagai penghasil metabolit sekunder dengan aktivitas biologi sebagai antijamur.

\section{Metode Penelitian}

\section{Bahan tumbuhan}

Bahan tumbuhan berupa daun dan akar pandan wangi diperoleh dari Kebun Raya Bogor pada bulan November 2006. Identifikasi jenis dilakukan di Herbarium Bogoriense, Bidang Botani, Puslit Biologi LIPI.

\section{Isolasi jamur endofit}

Isolasi jamur endofit dari pandan wangi dilakukan dengan metode yang sama dengan laporan terdahulu (Agusta et al., 2006). Daun dan akar dari masing pandan wangi dicuci dengan air sampai bersih, lalu dipotong-potong dengan ukuran panjang sekitar $5-7 \mathrm{~cm}$. Permukaan daun dan akar yang telah dipotong, selanjutnya disterilisasi dengan cara merendamnya dalam $75 \%$ etanol selama 2 menit, 5.3\% natrium hipoklorit selama 5 menit dan kembali dengan $75 \%$ etanol selama setengah menit. Daun yang telah disterilkan permukaannya tersebut kemudian dipotong dengan ukuran panjang sekitar $0.5 \mathrm{~cm}$, sedangkan bagian akar, setelah dipotong dengan ukuran panjang $1 \mathrm{~cm}$, kemudian dibelah dua lalu ditaruh di atas medium cornmeal malt agar (CMMA) yang mengandung kloramfenikol dengan konsentrasi $0.05 \mathrm{mg} / \mathrm{ml}$. Selanjutnya diinkubasi pada suhu $27^{\circ} \mathrm{C}$ selama 1 - 2 minggu. Setelah tumbuh, setiap koloni jamur selanjutnya dipindah/disubkultur beberapa kali ke medium potato dextrose agar (PDA) sampai diperoleh koloni murni.

\section{Identifikasi jamur endofit}

Identifikasi karakter morfologi jamur didasarkan pada panduan Barnett (1955), Ellis (1971), Domsch et al., (1980), Sutton (1980), Webster (1980), Barnett dan Hunter (1998). Identifikasi jamur dilakukan dengan mengamati ciri dan karakter morfologi baik secara makroskopis maupun secara mikroskopis dari koloni jamur yang ditumbuhkan di atas PDA pada temperatur ruang. Secara makroskopis karakter yang diamati meliputi; warna dan permukaan koloni (granular, seperti tepung, menggunung, licin), tekstur, zonasi, daerah tumbuh, garis-garis radial dan konsentris, warna balik koloni (reverse color), dan tetes eksudat (exudate drops). Pengamatan secara mikroskopis dilakukan dengan bantuan mikroskop Nikon eclips 80i yang meliputi ada tidaknya septa pada hifa, pigmentasi hifa, clamp connection, bentuk dan ornamentasi spora (vegetatif dan generatif), bentuk dan ornamentasi tangkai spora.

\section{Kultivasi isolat jamur endofit}

Isolat jamur endofit, masing-masing ditumbuhkan pada dua jenis medium cair (masing-masing $30 \mathrm{ml}$ ) yaitu medium potato dextrose broth (PDB) dan medium "glucoseexstract yeast-peptone" (GYP, 20 g glukosa, 1 $\mathrm{g}$ ekstrak yeast, $5 \mathrm{~g}$ peptone, $0.5 \mathrm{~g} \mathrm{~K}_{2} \mathrm{HPO}_{4}, 0.5$ $\mathrm{g} \mathrm{MgSO}_{4} 7 \mathrm{H}_{2} \mathrm{O}, 0.01 \mathrm{~g} \mathrm{FeSO}_{4} 7 \mathrm{H}_{2} \mathrm{O}, 1000 \mathrm{ml}$ $\mathrm{H}_{2} \mathrm{O}$ ), kemudian diinkubasi pada temperatur ruang $\left(26-29^{\circ} \mathrm{C}\right)$. Setelah 21 hari, seluruh medium pertumbuhan berikut biomassa diekstraksi dengan etil asetat, dan selanjutnya 
dipekatkan dengan penguap putar. Produksi metabolit sekunder oleh jamur endofit dianalisis dengan teknik kromatografi lapis tipis (KLT) menggunakan plat KLT GF 254 (0.2 mm, Merck), dengan penampak noda sinar UV $254 \mathrm{~nm}, 1 \% \mathrm{CeSO}_{4} / 10 \% \mathrm{H}_{2} \mathrm{SO}_{4}$ dan $10 \%$ vanilin $/ \mathrm{H}_{2} \mathrm{SO}_{4}$.

\section{Uji aktivitas antijamur}

Ekstrak etil asetat dari kultur jamur endofit pada medium PDB dan GYP, masingmasing dilarutkan dalam aseton dengan konsentrasi $30 \mathrm{mg} / \mathrm{ml}$. Kemudian paper disc yang telah disterilkan direndam dalam ekstrak etil asetat tersebut selama 5 menit. Setelah paper disc dikeringanginkan selama 20 menit (untuk menghilangkan aseton), paper disc yang telah mengandung ekstrak tersebut diletakkan di atas medium PDA yang sebelumnya telah diinokulasi dengan Saccharomyces cerevisiae (LIPIMC 0070), Fusarium oxysporum (LIPIMC 0091) dan Candida tropicalis (LIPIMC 0222). Selanjutnya diinkubasi pada temperatur kamar $\left(26-29^{\circ} \mathrm{C}\right)$ selama seminggu. Aktivitas antijamur dari ekstrak ditandai dengan terbentuknya zona bening disekeliling paper disc.

\section{Analisis GC-MS}

Ekstrak etil asetat dari kultur jamur endofit yang memperlihatkan aktivitas antijamur, selanjutnya dianalisis dengan teknik kromatografi gas dan tandem spektroskopi masa (GC-MS/MS, Saturn 2000, Varian) yang menggunakan kolom VF-17ms $(30 \mathrm{~m}$ x 0.25 $\mathrm{mm}$, Varian). Untuk analisis ini diterapkan temperatur kolom yang terprogram dari $80^{\circ} \mathrm{C}(3$ menit) dinaikkan menjadi $150^{\circ} \mathrm{C}$ dengan kecepatan kenaikan suhu $5^{\circ} \mathrm{C} /$ menit, dan selanjutnya suhu kolom dinaikkan sampai $275^{\circ} \mathrm{C}$ dengan kecepatan kenaikan suhu $3^{\circ} \mathrm{C} /$ menit, sedangkan temperatur injektor adalah $275^{\circ} \mathrm{C}$. Komponen kimia yang terdeteksi pada analisis ini diidentifikasi dengan membandingkan spektrum massa senyawa target dengan spektrum massa pada database (NIST, Wiley).

\section{Hasil dan Pembahasan}

Untuk isolasi jamur endofit dari pandan wangi dilakukan pada dua organ tumbuhan berupa daun dan akar. Pemilihan terhadap kedua organ berupa daun ditujukan untuk mengetahui biodiversitas jamur pada organ tumbuhan yang terdekat dengan sistim respirasi dan relatif jauh dari tanah dan organ akar yang terdekat atau berkontak langsung dengan tanah. Dari proses isolasi diperoleh 9 isolat jamur endofit yang terdiri dari 2 isolat (PWD1 dan PWD2) berasal dari organ daun dan 7 isolat (PWA1 PWA7) berasal dari organ akar.

Isolat jamur PWD1 membentuk koloni seperti kapas berwarna hitam pada media PDA dan bagian bawah koloni berwarna coklat tua kehitaman. Miselia berwarna coklat tua dan bersepta. Konidiofor bersepta, dan agak membengkok pada bagian ujungnya. Konidia berbentuk elips atau silindris, berwarna gelap dan bersepta semu (pseudosepta) 3 atau lebih. Konidia dari jamur ini agak sedikit membengkok dan membulat pada bagian ujungnya. Berdasarkan pengamatan morfologi isolat jamur endofit PWD1 adalah Drechslera sp. (Gambar 1A).

Jamur endofit isolat PWD2 membentuk koloni seperti kapas, berwarna abu-abu tua dengan kumpulan acervuli berwarna hitam pada media PDA. Bagian bawah koloni berwarna putih keabu-abuan. Secara mikroskopis terlihat bahwa acervuli berbentuk seperti cakram atau seperti bantalan dan berwarna hitam. Terdapat seta/duri-duri diantara konidiofor. Konidia transparan, berbentuk membulat/ elips/ silindris. Berdasarkan pengamatan morfologi isolat jamur endofit PWD2 diidetifikasi sebagai Colletotricum sp. PWD2 (Gambar 1B).

Secara makroskopis isolat jamur endofit PWA3 yang berasal dari organ akar, pada media PDA koloni berbentuk seperti kapas berwarna putih. Bagian bawah koloni berwarna kuning muda. Pengamatan secara mikroskopis memperlihatkan bahwa isolat jamur PWA3 memiliki hifa transparan, bersepta, konidiofor monofialid atau polifialid. Makrokonidia jamur ini berbentuk bulan sabit dan bersepta 3-5. Jamur ini termasuk ke dalam genus Fusarium (Gambar 1C). 
Isolat jamur endofit PWA4 memperlihatkan morfologi yang identik dengan isolat Colletotricum sp. PWD2 yang mengindikasikan bahwa isolat PWA4 tersebut adalah jamur yang tergolong ke dalam genus Colletotricum. Isolat-isolat jamur endofit lainnya yaitu PWA1, PWA2, PWA5, PWA6 dan PWA7 yang diisolasi dari $P$. amarylifolius berupa miselia steril yang tidak menghasilkan organ-organ spesifik untuk diidentifikasi berdasarkan karakter morfologi.

Hasil skrining produksi metabolit sekunder oleh masing-masing isolat jamur endofit dilakukan dengan jalan kultivasi masing-masing isolat jamur di dalam medium PDB dan GYP. Analisis KLT ekstrak etil asetat masing-masing kultur jamur endofit tersebut memperlihatkan profil metabolit yang bervariasi satu sama lain (data tidak ditampilkan). Dari uji daya antijamur memperlihatkan bahwa hanya ekstrak etil asetat kultur jamur isolat PWA1, PWA-2 dan Colletotricum sp. PWD2 di dalam medium GYP yang memperlihatkan aktivitas menghambat pertumbuhan Saccharomyces cerevisiae. Aktivitas antijamur ekstrak PWD2 lebih lemah dibanding kedua ekstrak lainnya. Aktivitas antijamur tersebut ditandai dengan terbentuknya zona bening disekeliling paper disc yang mengandung ekstrak etil asetat kultur jamur endofit tersebut.

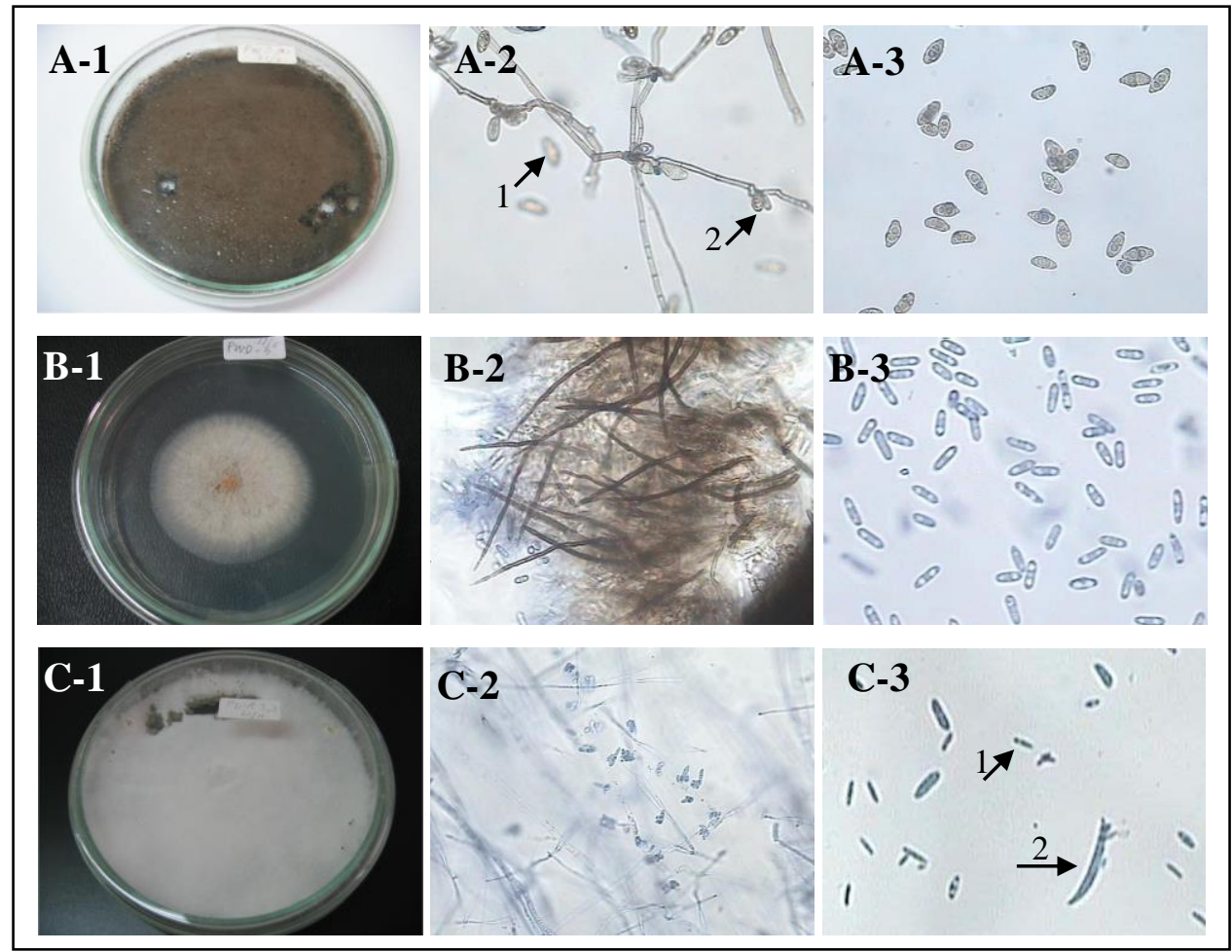

Gambar 1. Isolat jamur endofit Drechslera sp. PWD1 (A). A-1: Koloni berbentuk kapas berwarna coklat tua kehitaman, A-2: konidiofor (panah 1) dan bekas dudukan konidia (panah 2, 400x), A-3: unicellular konidia (400x). Isolat jamur endofit Colletotricum sp. PWD2 (B). B-1: Koloni berbentuk kapas berwarna abu-abu tua, B-2: seta atau duri yang terbentuk di antara konidiofor, B-3: konidia (400x). Isolat jamur endofit Fusarium sp. PWA3 (C). C-1: Koloni yang berbentuk seperti kapas berwarna putih, C-2: konidiofor berbentuk monofialid (400x), C-3: mikrokonidia (panah 1) dan makrokonidia (panah 2, 400x). 
Ekstrak etil asetat dari kultur jamur endofit PWA2 yang memperlihatkan aktivitas antijamur melawan $S$. cerevisiae, selanjutnya dianalisis dengan kombinasi teknik kromatografi gas dan spektrometri masa (GCMS). Hasil analisis memperlihatkan bahwa kultur jamur tersebut mengandung eugenol (2, Gambar 2). Eugenol (2) merupakan antibiotika alami yang telah dikenal sejak lama (Lee et al., 2007; Chami et al., 2004) yang merupakan komponen karakteristik minyak cengkeh. Besar kemungkinan bahwa senyawa inilah yang bertanggung jawab terhadap aktivitas antifungal melawan $S$. cerevisiae ekstrak etil asetat kultur jamur endofit PWA2 tersebut.

Bertolak belakang dengan laporan pada beberapa literatur (Tombe et al., 1993) yang menyebutkan bahwa eugenol juga memiliki kemampuan untuk menghambat pertumbuhan Candida tropicalis dan Fusarium oxysporum, ekstrak kultur jamur endofit PWA2 tidak memperlihatkan aktivitas penghambatan terhadap kedua jenis mikroba di atas. Terdapat dua kemungkinan penyebab perbedaan ini. Pertama adalah rendahnya konsentrasi eugenol di dalam ekstrak uji, atau berada di bawah nilai minimal inhibitor concentration (MIC) terhadap $C$. tropicalis dan $F$. oxysporum yaitu sebesar $12 \mu \mathrm{g} / \mathrm{ml}$ (Jurd et al., 1970) dan 300 $\mu \mathrm{g} / \mathrm{ml}$ (Tombe et al., 1993) berturut-turut, sehingga tidak memberikan efek penghambatan terhadap pertumbuhan kedua mikroba tersebut. Kedua adalah bahwa strain kedua mikroba yang digunakan dalam penelitian ini memang memiliki ketahanan yang relatif lebih tinggi terhadap eugenol dibanding strain mikroba yang dilaporkan pada literatur tersebut. Untuk itu masih diperlukan klarifikasi lebih lanjut dengan melakukan uji sensitifitas kedua strain mikroba ini terhadap eugenol.

Di samping mengandung eugenol (2), hasil analisis GC-MS ekstrak etil asetat kultur jamur endofit PWA2 juga mengandung beberapa komponen kimia lainnya. Namun hanya dua senyawa lainnya yang teridentifikasi dengan database NIST dan Wiley library, yaitu 3-oksobutiramida (1) dan 4,6-dihidroksi-1,1dimetil-1,2,3,4-tetrahidro isokuinolin (3), sedangkan hasil analisis dan karakterisasi komponen kimia dari ekstrak etilasetat kultur jamur endofit PWA1 dan Colletotricum sp. PWD2 akan dilaporkan dalam artikel terpisah (manuskrip sedang dipersiapkan).

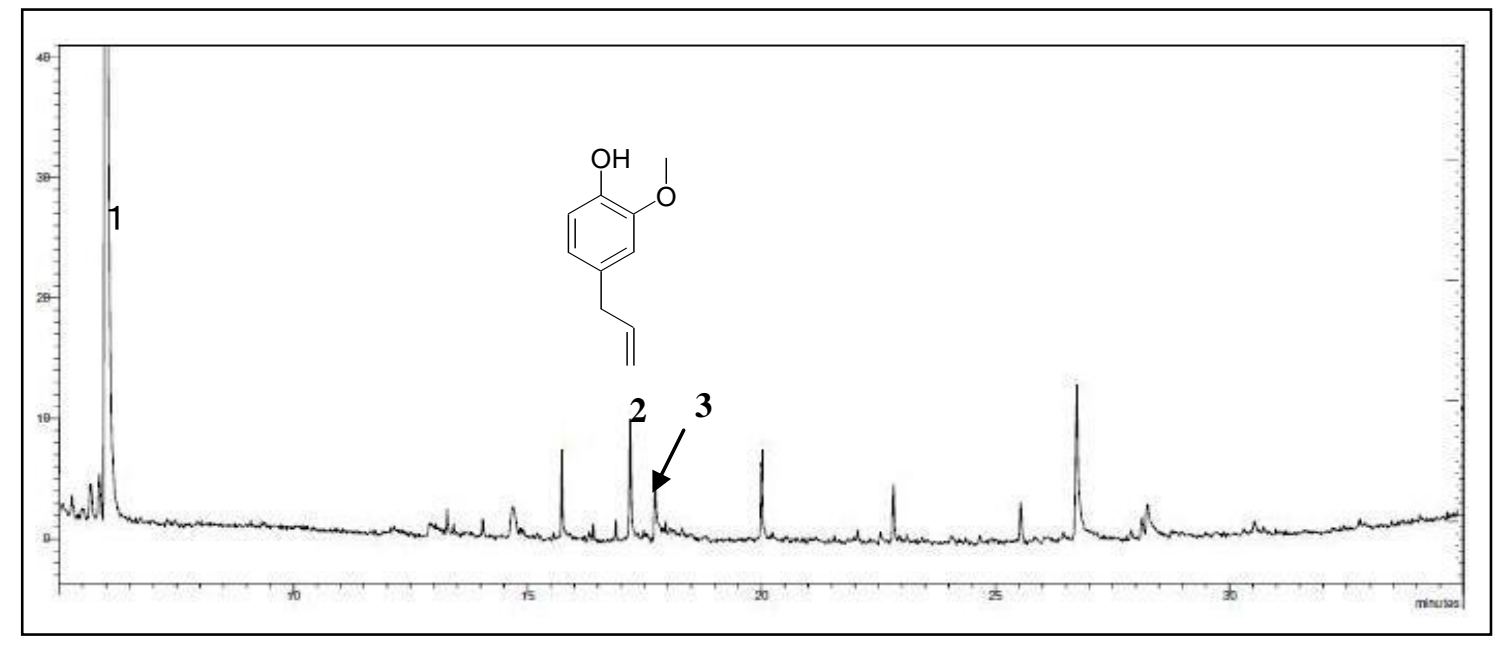

Gambar 2. Kromatogram hasil analisis GC-MS ekstrak etil asetat kultur jamur endofit PWA2 di dalam medium GYP selama 3 minggu (statis) pada temperatur $26-28^{\circ} \mathrm{C}$. 


\section{Kesimpulan dan Saran}

\section{Kesimpulan}

Dari kegiatan penelitian ini berhasil diperoleh sembilan isolat jamur endofit yang terdiri dari dua isolat (Drechslera sp. PWD1 dan Colletotricum sp. PWD2) berasal dari organ daun dan tujuh isolat (PWA1, PWA2, Fusarium sp. PWA3, Colletotricum sp. PWA4, PWA5, PWA6, PWA7) berasal dari organ akar pandan wangi. Ekstrak etil asetat kultur jamur endofit PWA2 memperlihatkan aktivitas sebagai antifungal terhadap $C$. cerevisiae dengan eugenol sebagai komponen bioaktifnya.

\section{Saran}

Pada penelitian ini jumlah eugenol yang diproduksi oleh jamur endofit PWA2 masih sangat rendah. Untuk itu masih diperlukan optimasi produksi eugenol dengan jalan melakukan modifikasi medium tumbuhan dan parameter kultivasi lainnya. Di samping itu perlu juga dilakukan klarifikasi terhadap sensitifitas eugenol terhadap $C$. tropicalis (LIPIMC 0222) dan F. oxysporum (LIPIMC 0091).

\section{Ucapan Terima Kasih}

Sebagian penelitian ini didanai oleh DIPA Etnobiologi Pandanaceae, Puslit Biologi LIPI TA 2006 dan 2008.

\section{Daftar Pustaka}

Agusta, A., Ohashi, K. and Shibuya, H. 2006. Composition of the endophytic fungi isolated from the tea plant Camelia sinensis. J. Nat. Med. 60 (3): 268-272.

Bacon, C.W. and White Jr, J.F. 2000. Microbial endophytes. Marcel Dekker, New York.

Barnet, H.L. 1955. Illustrated Genera of Imperfect Fungi. $2^{\text {nd }}$ ed. Minneapolis: Burgess Publishing Company.
Barnett, H.L. and Hunter, B.B. 1998. Illustrated genera of imperfect fungi. $4^{\text {th }}$ ed. USA: Prentice-Hall, Inc.

Chami, F., Chami, N., Bennis, S., Trouillas, J. and Remmal, A. 2004. Evaluation of carvacrol and eugenol as prophylaxis and treatment of vaginal candidiasis in an immunosuppressed rat model. J. Antimicrob. Chemother 45: 909-914.

Domsch, K.H., Gams, W. and Anderson, T.H. 1980. Compendium of soil fungi. Vol 1. Academic Press, London.

Ellis, M.B. 1971. Dematiaceous hyphomycetes. England: Commonwealth Mycological Institute.

Hawksworth, D.L. 1991. The Fungal Dimension of Biodiversity: Magnitude, significance, and conservation, Mycol. Res. 95: 641-655.

Hawksworth, D.L. and Rossman, A.Y. 1997. Where are all the undescribed fungi, Phytopathol 87 (9): 888-891.

Jurd, L., King, A.D., Martinez, J. and Stanley, W.L. 1973. Cinnamyl phenols usefull as antimicrobial agents. US Patent: 3,745,222.

Lee, S.J., Han, J.K., Lee, G..S., Park, M.J., Choi, I.G., Na, K.J. and Jeung, E.B. 2007. Antifungal effect of eugenol and nerolidol against Microsporum gypseum in a Guinea pig model. Biol. Pharm. Bull. 30: 184-188.

Strobel, G. and B. Daisy. 2003. Bioprospecting for Microbial Endophytes and Their Natural Products. Microbiol.Mol. Biol. Rev., 67, 491502.

Sutton, B.C. 1980. The Coelomycetes. Commonwealth Mycological Institute, England.

Tan, R.X. and Zou, W.X. 2001. Endophytes: a Rich Source of Functional Metabolites, Nat. Prod. Rep. 18: 448-459.

Tombe, M., Kobayashi, K., Ma'mun, Triantoro, Oniki, M. and Matsumoto. 1993. The role of eugenol in suppression of stem rot disease of vanilla. $J$. Industrial Crops Res. 6: 12-20.

Webster, J. 1980. Introduction to fungi. $2^{\text {nd }}$ ed. Cambridge University Press, Melbourne.

Zhang, H.W., Song, Y.C. and Tan, R.X. 2006. Biology and Chemistry of Endophytes. Nat. Prod. Rep. 23: 753-771. 